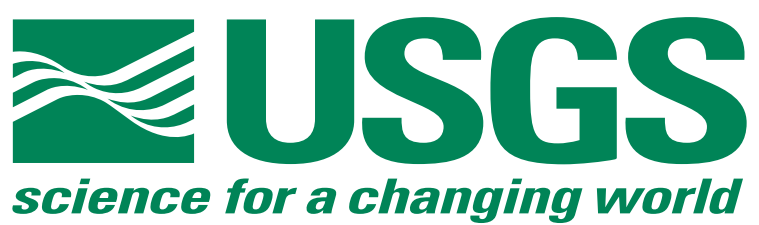

\title{
Deaggregation of U.S. Seismic Hazard Sources: The 2002 Update
}

by S.C. Harmsen, A. D. Frankel, and M. D. Petersen

This report is preliminary and has not been reviewed for conformity with U.S. Geological Survey editorial standards or with the North American Stratigraphic Code.

Any use of trade, firm, or product names is for descriptive purposes and does not imply endorsement by the U. S. Government.

Open-File Report 2003-03-440

U.S. Department of the Interior

U.S. Geological Survey 
Deaggregation of U.S. Seismic Hazard Sources: The 2002 Update

by S. C. Harmsen, A. D. Frankel, and M. D. Petersen, USGS

INTRODUCTION

ESSENTIAL BACKGROUND MATERIAL 4

$\begin{array}{ll}\text { DEFINITIONS OF TERMS } & 5\end{array}$

$\begin{array}{ll}\text { BINNING } & 6\end{array}$

QUANTIFICATION OF GROUND-MOTION UNCERTAINTY FROM FUTURE EARTHQUAKES

$\begin{array}{lr}\text { RESULTS } & 9\end{array}$

WUS SEISMIC HAZARD DEAGGREGATION MAPS: THE MODE 9

WUS SEISMIC HAZARD DEAGGREGATION MAPS: THE MEAN 11

California-Nevada Region Maps of Modal Source Parameters $\quad 13$

Oregon-Washington Region Maps of Modal Source Parameters 15

$\begin{array}{ll}\text { A Closer Look at Seismic Hazard in Portland, Oregon } & 17\end{array}$

Maps of Modal Source Parameters in the Intermountain Seismic Belt 18

CENTRAL AND EASTERN U.S. MODAL SOURCE PARAMETER MAPS 19

CENTRAL AND EASTERN U.S. MEAN SOURCE PARAMETER MAPS 21

New Madrid Seismic Zone Modal Source Parameters $\quad 22$

$\begin{array}{ll}\text { South Carolina Modal Source Parameters } & 23\end{array}$

$\begin{array}{ll}\text { SUMMARY } & 25\end{array}$

CONCLUSIONS AND DISCUSSION 25

$\begin{array}{ll}\text { ACKNOWLEDGEMENTS: } & 27\end{array}$ 
REFERENCES CITED

FIGURES 


\section{Introduction}

This document provides a nation-wide overview of seismic sources that contribute to the 2001-2002 update of the USGS Probabilistic Seismic Hazard Assessment (PSHA) (Frankel et al., 2002) in the form of deaggregated mean and modal sources for the $2 \%$ in 50 year probability of exceedance (PE) and the $10 \%$ in 50 year PE for sites in the conterminous USA. The primary purpose of this document is to provide information to urban planners and seismic-resistant design engineers about seismic sources that might sensibly be considered when planning and designing.

Mean and modal seismic sources vary with spectral period. Source deaggregations associated with peak horizontal ground acceleration (PGA), and with 2.0-s, 1.0-s. 0.2-s and 0.1-s spectral acceleration (SA) are performed, and maps are presented and contrasted for these periods of motion. Maps of mean and modal source parameters for 0.3-s and 0.5-s SA are also available from the first author (harmsen@usgs.gov).

\section{Essential Background Material}

Documentation for the 2002 Update of the National Seismic Hazard Maps (OFR 02-420) (A. Frankel and others, 2002) discusses the new models of seismic hazard, including newly recognized sources, as well as new treatments of previously recognized sources. The reader should be familiar with that document, available on the web at http://pubs.usgs.gov/of/2002/ofr-02-420, in order to better understand the components of the PSHA model that affect mean and modal source parameters. The OFR also discusses the way modifications came to be made from the previous USGS PSHA (Frankel et al, 1996), mostly through a series of regional workshops and follow-up meetings, where experts provided current models of seismic hazards for their regions and current models of strongmotion attenuation. Other changes to the PSHA model made after publication of OFR 02-420, such as the extension of the maximum distance $(R)$ for calculating hazard for California A-faults from $200 \mathrm{~km}$ to $250 \mathrm{~km}$, are also included in the calculations of this report. This report's calculations include all modifications through October 2003 (version 6 of the PSHA model).

On national and broad regional map scales, deaggregation analysis can help to highlight changes from the previous PSHA maps, but site-specific hazard deaggregation is necessary to gain a better understanding of newly recognized sources and revised treatments of previously recognized sources. The USGS WWW URL, http://eqint.cr.usgs.gov/eq/html/deaggint2002.html allows the visitor to deaggregate the seismic hazard at any location in the conterminous USA using the 2002 PSHA model, for a wide variety of spectral periods and return times. 
That web site exhibits contributions from all sources at a specific site, along with the mean and modal source information provided in this report.

\section{Definitions of Terms}

This document uses deaggregation analysis definitions given in Harmsen et al., 1999; Harmsen and Frankel, 2001; and Harmsen, 2001. Three primary deaggregated source parameters are considered, (1), source-to-site distance, (2), magnitude, and (3), epsilon, or ground-motion (g.m.) uncertainty. These are denoted $R, \mathbf{M}$, and $\varepsilon_{0}$, respectively. $R$ initially is one of Rseis, Rrup, or Rjb (Abrahamson and Shedlock, 1997), or in some cases, $R$ is distance to the center of a cell within which a seismicity rate is defined. Rseis is the slant distance from the site to the nearest point on the part of the fault believed capable of generating strong motion. Rrup is the slant distance from the site to the nearest location on the modeled fault or portion of the fault that ruptures. Rjb is the nearest distance to the vertical projection of the fault (or portion of the fault that ruptures) to the free surface. A fourth distance metric, based on projecting the fault downdip into the Earth's mantle, is used to determine the hanging-wall term for the Abrahamson and Silva (1997) attenuation model. After binning takes place, $R$ is a hybrid distance. $\mathbf{M}$ is bold to indicate moment magnitude. The mean R, $\mathbf{M}, \varepsilon_{0}$ at a site averages over all sources considered in the PSHA model, and is independent of any binning definitions. The modal-event source is determined from the magnitude and distance bin that yields the largest contribution to the specified hazard. The mode is the mean $R, \mathbf{M}, \varepsilon_{0}$ of sources in that $R, \mathbf{M}$ bin. The mode is dependent on binning definitions. The largest bin contribution in this report ranges from less than $5 \%$ of the total to over $80 \%$ of the total, depending on site location, spectral period, and PE. Whether knowing the mode means knowing the model is strongly spatially dependent for "typical" PEs (2\% in 50 years or $10 \%$ in 50 years, for example) and specified spectral period. For the most part such statements are overgeneralizations likely to lead to misunderstanding when applied uncritically to seismic mitigation decision making.

The primary summation in PSHA is of mean rate of g.m. exceedance, which is mean rate of occurrence times conditional probability of g.m. exceedance given the occurrence of a seismic source, and given a set of attenuation models that predict the distribution of future ground motion from seismic sources. A "contribution" for a given PE, then, is the mean rate of exceedance for sources in a specific $\mathrm{R}, \mathrm{M}$ bin divided by the rate implied by the given $\mathrm{PE}$. A hazard contribution can be expressed as a fraction, as a percent, or in a more qualitative manner. Thus, the brief statement "the mode represents $50 \%$ of the hazard" is intended to mean, "potential sources in the modal R,M bin will produce, on average, half of the ground motions that exceed some specified g.m. level (i.e., "exceedances") in a randomly selected 50-year period." There is no claim about the relative likelihood of the mode versus other considered (or unconsidered) 
seismic hazard sources for any specific 50-year period, such as the next 50 years.

In this document, SA is pseudo-spectral acceleration with $5 \%$ damping (see Hudson, 1979). PGA is peak horizontal ground acceleration. SA, like PGA, is a peak-horizontal-motion indicator. Units for acceleration are percent $g$, where $g$ is the standard acceleration due to gravity, $9.8 \mathrm{~m} / \mathrm{s}^{2}$. For this report, lower-case sa is the logarithm of SA. The logarithm is a pervasive operator in PSHA because sa, when thought of as a random variable, is approximately normally distributed, i.e., SA is lognormally distributed.

Most USGS seismic hazard maps, including those of this report, pertain to motion at a site with firm-rock conditions. Firm rock is rock with average shearwave velocity of $760 \mathrm{~m} / \mathrm{s}$ in the upper 30 meters, putting it at the NEHRP B-C boundary. The word "motion" in this report generally refers to SA, although it may refer to PGA in some instances. In this document these terms are implicitly preceded by the adjective "probabilistic," if the authors are discussing future rather than recorded motion.

\section{Binning}

For the analysis underlying the maps presented below, and at the interactive deaggregation web site, the magnitude bin width is $0.2 \mathrm{Mw}$ units, reduced from $0.5 \mathrm{Mw}$ units of previous studies cited above. The magnitude-bin centers are at M 4.6,4.8, 5, 5.2,..., 9.

For this report (but not for the interactive deaggregation web site) the distance annular width, $\Delta R$, is $10 \mathrm{~km}$ from $0 \mathrm{~km}$ to $100 \mathrm{~km}, 50 \mathrm{~km}$ from 100 to $300 \mathrm{~km}$, $200 \mathrm{~km}$ from 300 to $500 \mathrm{~km}$, and $500 \mathrm{~km}$ from 500 to $1000 \mathrm{~km}$. $1000 \mathrm{~km}$ is the maximum considered distance for seismic hazard in the CEUS. The 1000-km limit is double that of the 1996 maps for random seismicity, but is the same for New Madrid Seismic Zone (NMSZ) sources. $200 \mathrm{~km}$ is the maximum considered source-to-site distance in the WUS west of the Rocky Mountains for most sources other than Cascadia sudduction, which has a 1000-km limit, and California A-faults, such as the San Andreas and Imperial faults. The maximum considered distance for hazard from California A-faults is $250 \mathrm{~km}$.

In some cases, such as Cascadia subduction and NMSZ mainshocks, locations of distant sources may be reasonably well known. In other cases, such as Central and Eastern U.S. random seismicity, potentially significant earthquakes may occur at a wide range of distances and azimuths. The relative importance of distant sources to regional and local sources is assessed by varying $\Delta R$, the distance bin width, with $\mathrm{R}$. For some regions that have very little earthquake threat, such as Minnesota and Wisconsin, we will see that the modal-source distance, given the above bin definition, can exceed $500 \mathrm{~km}$, with or without 
contributions from NMSZ. At the interactive deaggregation web site, the distancebin annular width remains constant. $\Delta \mathrm{R}$ is $10 \mathrm{~km}$ for seismically more active areas, and is $25 \mathrm{~km}$ elsewhere. Thus, the mode reported here and that reported at the web site may differ, due exclusively to different $\Delta \mathrm{R}$ definitions. The mean $\mathbf{M}, \mathbf{R}$, and $\varepsilon_{0}$, however, are the same here as at the web site for a given site, SA, and PE due to their definitions, given in Harmsen et al (1999). The mean is independent of bin details.

\section{Quantification of Ground-Motion Uncertainty from Future Earthquakes}

A variety of methods have been proposed for deaggregating ground-motion uncertainty given $\mathbf{R}$ and $\mathbf{M}$ for the exceedance of a specified ground motion. Two measures of ground-motion uncertainty are discussed in this report. These are (1), modal $\varepsilon_{0}$, or $\hat{\varepsilon}_{0}$, and (2), the average $\varepsilon_{0}$ for all sources that contribute to hazard, denoted mean $\varepsilon_{0}$ or $\bar{\varepsilon}_{0}$.

As in McGuire (1995), we define

$$
\varepsilon_{0 \mathrm{~A}}(S)=\left(\mathrm{sa}_{0}-\mu_{\mathrm{A}}\right) / \sigma_{\mathrm{A}},
$$

that is, the standardized value of $\mathrm{sa}_{0}=\log \left(\mathrm{SA}_{0}\right)$, or the number of standard deviations, from $\mathrm{sa}_{0}$ to the logarithmic mean ground motion, $\mu_{\mathrm{A}}$, for a specific source $S$, and attenuation model, $A$. $S A_{0}$ is the ground motion associated with a specific $\mathrm{PE}$, for example, the $2 \%$ in 50 year $\mathrm{PE}$. $\mathrm{SA}_{0}$ is what is mapped in reports such as Frankel et al. (1996) and Frankel et al. (2002). In general, any remarks about mean or modal sources implicitly contain the phrase, "for a given probability of exceedance (PE)," because these sources change, often dramatically, with PE.

When examining maps of mean or modal $\varepsilon_{0}$ it is helpful to be able to translate the mapped $\varepsilon_{0}$ values into simple, easy to communicate numbers. For concreteness, but in an approximate sense, if the modal-source $\varepsilon_{0}=1$ then the probabilistic motion is about 1.8 times the median motion expected from that source, whereas if $\varepsilon_{0}=-1$ then the median motion of that source is about 1.8 times the probabilistic motion. If $\varepsilon_{0}=0$, then the probabilistic motion equals the median motion of that source. Initially, $\varepsilon_{0}$ is a quantity that is determined from each attenuation model for a given source. However, a reported or binned or mapped $\varepsilon_{0}=0$ not only averages over sources in a (R,M) bin, but also weighs $\varepsilon_{0}$ that is computed for each attenuation model, $A$. Mathematically, epistemic weighting is the same thing as averaging. We average effects of the attenuation models for sources in a $(\mathrm{R}, \mathrm{M})$ bin.

For the modal-event $R, \mathrm{M}, \varepsilon_{0}$, denoted $\left(\hat{R}, \hat{M}, \hat{\varepsilon}_{0}\right)$, it is reasonable to suppose that $\mathrm{sa}_{0}$ approximately equals $\mu_{\mathrm{A}}+\hat{\varepsilon}_{0} \sigma_{\mathrm{A}}$, or, 


$$
S A_{0} \approx \exp \left(\mu_{A}+\hat{\varepsilon}_{0} \sigma_{A}\right)
$$

where, as stated before, $\mu_{\mathrm{A}}$ and $\sigma_{\mathrm{A}}$ are mean and standard deviation of the normal distribution of sa given $\hat{R}$ and $\hat{M}$. The right-hand side of (2) should be computed using an attenuation model $A$ that is used in the PSHA. The accuracy of the approximation in Eqn. (2) should improve as $\Delta \mathrm{R}$ and $\Delta \mathrm{M}$ (bin widths) decrease. However, for the mean $\mathrm{R}, \mathrm{M}, \varepsilon_{0}$, (which is the mode for largest possible bins), the relation of $\mathrm{SA}_{0}$ to the conditional distribution parameters is less likely to fit an equation like the following

$$
S A_{0} \approx \exp \left(\mu_{A}^{\prime}+\bar{\varepsilon}_{0} \sigma_{A}^{\prime}\right) .
$$

where $\mu_{\mathrm{A}}^{\prime}$ and $\sigma_{\mathrm{A}}^{\prime}$ are the mean and standard deviation of the ground-motion prediction equation, respectively, given $\bar{R}$ and $\bar{M}$. For a randomly chosen site in the U.S.A., and a randomly chosen attenuation model used in the PSHA, the most likely relationship to actually hold is

$$
\exp \left(\mu_{A}^{\prime}+\bar{\varepsilon}_{0} \sigma_{A}^{\prime}\right)<\exp \left(\mu_{A}+\hat{\varepsilon}_{0} \sigma_{A}\right)<S A_{0},
$$

although for some sites and for some specifically chosen attenuation models, it is possible that

$$
\exp \left(\mu_{A}^{\prime}+\bar{\varepsilon}_{0} \sigma_{A}^{\prime}\right)>\exp \left(\mu_{A}+\hat{\varepsilon}_{0} \sigma_{A}\right)>S A_{0} .
$$

The left side of inequality (4) is at many sites and for several attenuation models less than half the right side, a substantial difference. Inequality (5) is much less likely to be true at a randomly chosen site for a typical PE. One region where inequality (5) is sometimes true is western Oregon for the 1 s SA, the $2 \%$ in 50 year PE, and the Sadigh et al. (1997) attenuation model. In this instance, the difference between the left and right sides of Eqn. (5) is a few percent.

The distribution of probabilistic seismic sources for many if not most sites in the U.S. is multi-modal. That is, the distribution does not tend to concentrate strongly around any single magnitude and distance. At sites where the difference between $\exp \left(\mu+\bar{\varepsilon}_{0} \sigma\right)$ and $\mathrm{SA}_{0}$ is small, we may usually infer that the distribution of probabilisitic sources is approximately uni-modal. For the western Oregon region just mentioned, the mode is a M8.3 or M9 subduction earthquake, and other sources tend to contribute little to the seismic hazard.

How significant is the modal event? A probabilistic answer might be given as the ratio of the modal-source contribution to the total hazard. This ratio whether for the mode or any other source is sometimes called the "source contribution factor." The modal source contribution factor, or MCF, is mapped in the California-Nevada section below.

Mean $\varepsilon_{0}$ rises monotonically with probabilistic ground motion, which of course increases in a mean sense as the probability of exceedance decreases. For a given modal-source bin, modal $\varepsilon_{0}$ rises with probabilistic ground motion until a new contributing source achieves dominance, at which moment modal $\varepsilon_{0}$ falls abruptly. The distinctly different ways in which the mean and the mode vary with probabilistic ground motion is examined in the section on Portland Oregon below. 
The USGS interactive deaggregation web sites provides considerable detail about the distribution of $\varepsilon$ along with magnitude and distance for probabilistic sources at any specified site in the USA. The "1996 site" includes Alaska and Hawaii. USGS PSHA for Alaska and Hawaii will be updated in the future. Also, Puerto Rico site PSHA deaggregation is now possible using the new USGS model (Mueller et al., 2003) and is also available at the 2002 interactive deaggregation web site.

\section{Results}

Deaggregated seismic hazard mean and modal $\mathrm{R} \mathbf{M}$ and $\varepsilon_{0}$ are presented for the WUS and for sub-regions of the WUS, and for the CEUS and sub-regions of the CEUS $\left(100^{\circ}\right.$ West defines the boundary between west and east for these maps). Although the maps are presented separately for these three parameters, the modal-source $\left(R, \mathbf{M}, \varepsilon_{0}\right)$ is a single entity, i.e., the modal $R \mathbf{M}$ and $\varepsilon_{0}$ maps should be considered together for a correct understanding of the modal source. For example, for a site in eastern Washington, M9 may be the modal source magnitude and several hundred $\mathrm{km}$ may be the modal source distance. Such a combination implies that a Cascadia megathrust event is the dominant source, i.e., the source that contributes the largest fraction of ground-motion exceedances in a random 50-year interval to that site, at that spectral period, for that PE.

For those who are interested in the names of and details about the sources that contribute to the seismic hazard in the USGS model, the interactive deaggregation web site cited above should be helpful. At that site, one can learn the relative contributions of all the major contributors to hazard at the site. Also, all individual fault sources (if any) that contribute more than $5 \%$ of the exceedances of ground motion are listed along with those faults' mean magnitude, distance and $\varepsilon_{0}$ at the site location specified. Also, at that web site, one can perform a geographic deaggregation to look at the locations of faults and other sources that contribute to the hazard at the site, and look at the relative contributions plotted on a map centered at the site.

\section{WUS Seismic Hazard Deaggregation Maps: The Mode}

Maps of the modal-event magnitude, or $\hat{M}$, for the WUS are shown in Figure 1 . The left side of Figure 1 exhibits $\hat{M}$ for 1-s SA and the right side exhibits $\hat{M}$ for 0.2 -s SA. All modes are with respect to the $2 \%$ in 50 year PE. By plotting two periods' data together we can see how in general, large-M sources tend to remain modal to greater distances for longer-period waves. For example, M8.3 and M9 Cascadia sources dominate the hazard in most of Oregon and Washington for 1-s SA, but dominate only in western Washington, principally, the 
Olympic Peninsula and Columbia River Gorge, for 0.2-s SA. The Seattle fault dominates the 1s hazard for many sites in Seattle. The M9 Cascadia source also dominates northwestern California's seismic hazard, extending far into the Great Valley for the 1-s SA. Figure 1 shows that at sufficient distance from the Pacific coast states, M6.5 to M6.9 sources tend to dominate the hazard at $1 \mathrm{~s}$, and M5 to 6 tend to dominate the hazard at $0.2 \mathrm{~s}$, with several locations having highermagnitude modes, and some lower. In California, modal-event magnitude is often associated with a nearby fault, the most prominent of which is the San Andreas. San Andreas fault modal magnitudes are as great as 8 in northern California and 7.9 in southern California, although alternate-scenario magnitudes can exceed M8.3. California and Pacific Northwest modal events will be shown in greater detail in figures that follow.

Modal-source distance, or $\hat{R}$, for 1-s and 0.2-s spectral periods is shown in Figure 2. Units for $R$ are $\mathrm{km} . \hat{R}$ is often less than 5 to $10 \mathrm{~km}$ at sites near WUS Quaternary faults. $\hat{R}$ is computed using a nearest-distance-to-fault metric. $\hat{R}$ can be large, as great as $1000 \mathrm{~km}$, if the megathrust source dominates the hazard at a particular site, as is the case at a few locations in northern Montana. In this figure, as in several figures that follow, a saturation color (in this case dark blue) represents parameter values greater than the maximum shown in the legend (here $500 \mathrm{~km}$ ).

Modal-source $\varepsilon_{0}$, or $\hat{\varepsilon}_{0}$, for those spectral periods is shown in Figure 3 . In much of Nevada, Arizona, New Mexico, Colorado, Idaho, Utah, and Oregon, the dominant source is a relatively long-recurrence-time fault. The probabilistic ground motion can be low for sites on or very near these faults. The $\varepsilon_{0}$ map uses warm and hot colors (reds and browns) to indicate probabilistic ground motion well below the median of the modal source for those sites. The $\varepsilon_{0}$ topic is discussed more fully in Harmsen (2001) and in the conclusions to this report.

Modal magnitude maps are again shown for the $2 \%$ in 50 year PE for the WUS in Figure 4. The left-side map shows data for the 2-s spectral period and the right side for 0.1-s. Two s and $0.1 \mathrm{~s}$ are the longest and shortest SA periods, respectively, calculated by the USGS national seismic hazard mapping project (excluding PGA). A comparison of Figure 4 and Figure 1 indicates that a slightly greater region encompassing California's Great Valley has a modal San Andreas source for the 2-s compared to the 1-s SA. In the east part of the WUS, an M7.7 New Madrid source everywhere dominates the 2-s hazard out to the maximum source-to-site distance of $1000 \mathrm{~km}$, but in only a few places for the 1-s hazard. For the 0.1-s SA mode compared to the 0.2-s SA mode, the modal event magnitude tends to be lower for the shorter-period motion, and frequently $\hat{M} \approx 5$ east of the Rocky Mountains. Except for these differences, the maps of Figure 4 are a recapitulation of those of Figure 1, and therefore, WUS PSHA for these periods will not be considered further here. 
The PGA modal-event $\mathbf{M}$ is shown for the WUS in Figure 5 , the left side for the $2 \%$ in 50 year PE, and the right side for the $10 \%$ in 50 year PE. The PGA modalevent R for the WUS is shown in Figure 6. By showing two return-period modalevent maps together, we can see the effect of increasing or decreasing the probabilistic motion (which rises with mean return time) on the mode. Long recurrence-time faults, common in Nevada and parts of Arizona, New Mexico, Utah, and Colorado, are frequently modal sources at the $2 \%$ in 50 year PE, but cease to be as significant for the $10 \%$ in 50 year PE. Note also that Cascadia subduction M9 sources tend to extend their modal influence further east for the $10 \%$ in 50 year PE, because Cascadia subduction has an estimated recurrence time that is relatively short compared to that of many of the local sources of eastern Washington, Idaho, and elsewhere, which often dominate the $2 \%$ in 50 year PE modal-event maps, at least at short spectral periods. In general, decreasing the PE tends to increase the influence of local sources compared to more regional sources (Harmsen et al, 1999) in terms of contributions to the probabilistic motion. As long as the mean source recurrence time is relatively short compared to the return period under consideration, that source will tend to be important in the PSHA, often modal if close to the site, .large in magnitude, or both.

Figures $\underline{5}$ and $\underline{6}$ indicate that in many parts of the WUS, there is little change in the modal-source description associated with PGA for the 475-year and 2475year return times. However, there are many sites at which closer smaller sources may contribute comparably to a given probabilistic motion as more distant larger sources for a given PE. At such sites, going from this PE to another in a deaggregation analysis will often result in a shift in the mode. Decisions about appropriate scenario earthquakes at these sites contend with multi-modal seismic hazard distributions for a given frequency of motion. One purpose of the interactive deaggregation web site is to assist in the determination if any given U.S. site has such a distribution of probabilistic sources.

\section{WUS Seismic Hazard Deaggregation Maps: The Mean}

The mean $\mathbf{M}$ or $\bar{M}$ (read, Mbar) for sites in the WUS is shown in Figure 7, for 1-s SA on the left and for 0.2-s SA on the right. These maps are for the $2 \% \mathrm{PE}$ in 50 years. $\bar{M}$ is larger at $1 \mathrm{~Hz}$ than at $5 \mathrm{~Hz}$ because larger sources tend to produce seismograms that are enriched in the longer period vibrations. If the mean magnitude, distance pair is close to the mode, we can usually infer that the distribution of hazard sources is reasonably symmetric about the mean. At typical PE levels, such as $2 \%$ and $10 \%$ in 50 years, most sites receive contributions from a broad distribution of source magnitudes and distances. The approximate equality of the mean and mode does not imply that only one source strongly dominates the seismic hazard at a site, although this statement becomes increasingly true at very low PE levels. 
Like the modal $\mathbf{M}$, the mean $\mathbf{M}$ for 1-s SA is often significantly greater than that for 0.2-s SA for a given PE. This is true for much of the WUS, as indicated in Figure 7. This can be partly understood by comparing median motion for 1s with median motion for PGA and a given PE. In this case $\mu(\mathrm{M} 7+, 1 \mathrm{~s})>\mu(\mathrm{M} 7+, \mathrm{PGA})$ but $\mu$ (M6.5-,PGA)> $\mu$ (M6.5-,1s), where $\mu$ is the median predicted motion for a given attenuation model and a given source recorded at a given site. These inequalities are meant to indicate that the ratio of median motion for longer period SA to shorter period SA progressively rises with magnitude, where other conditions are fixed. Thus, at a given level of probabilistic ground motion, larger sources are more important contributors at longer periods.

A comparison of Figure 7 with Figure 1 suggests that Cascadia subduction sources, although modal, represent only a small fraction of the seismic hazard in much of Washington and Oregon. In other words, Cascadia subduction earthquakes often have a low MCF in much of the Pacific Northwest. The fact that the mean $\mathbf{M}$ is 7 for 1-s SA in much of eastern Washington, while the modal $\mathbf{M}$ is 9 indicates that relatively low-magnitude local sources (M5 to 6 ) are quite important contributors to the 1-s SA hazard. This is not surprising, because those lower-magnitude sources can be modal for the 0.2-s SA in eastern Washington. Similar kinds of inferences can be made at many other locations of the WUS by comparing Figure 7 with Figure 1.

Approximate locations of fault lines often may be inferred better from $\bar{M}$ maps for the high-frequency $(5 \mathrm{~Hz}$, or $0.2 \mathrm{~s}) \mathrm{SA}$ of Figure 7 than for the intermediatefrequency $(1 \mathrm{~Hz}$, or $1 \mathrm{~s}) \mathrm{SA}$. Mainly, lower magnitude gridded sources are more significant (i.e., produce more ground-motion exceedances) at short periods than at longer periods for a given site and PE, producing a larger contrast in $\bar{M}$ maps such as Figure 7 as site location moves away from the fault, whose magnitude distribution is typically larger than those of gridded sources. Also, a lesser spatial magnitude variation in the longer-period map is explained in part by the fact that most attenuation models have larger aleatory $\sigma$ for longer period SA, tending to smear or mix source influences more as spectral period increases. Fault traces will be shown on figures that follow.

Mean R or $\bar{R}$ for sites in the WUS is shown in Figure 8, for 1-s SA on the left and for 0.2-s SA on the right. These maps again show the greater influence of more distant sources for longer period probabilistic SA than for shorter period SA. Inland from the west coast of the U.S., investigators such as Youngs et al (1997) develop their models from ground motion records from subduction sources elsewhere, such as Latin America, and the national seismic hazard mapping project uses these models to predict Cascadia strong motion. For WUS sites at relatively great distances from the Pacific coast, the mean source description is far less sensitive than the mode to potential errors in predicted intermediate to long-period motion from these Cascadia sources. Taken collectively, local gridded sources tend to be far more significant to the intermediate to long-period hazard than Cascadia subduction sources east of about $120^{\circ} \mathrm{W}$, even though 
individual gridded-source bins may be relatively small. Newly included faults such as the Saddle Mountain fault in central Washington, while often not modal at the $2 \%$ in 50 year PE, make significant contributions to the mean hazard at many sites in the Pacific Northwest.

Mean $\varepsilon_{0}$ or $\bar{\varepsilon}_{0}$ for sites in the WUS is shown in Figure 9 , for 1-s SA. On the right side of Figure 9 we show, for the first time in this report, a comparison of the 2002 map data with the 1996 data, by subtracting $\bar{\varepsilon}_{0}$ for 1996 data from $\bar{\varepsilon}_{0}$ for 2002 data. A resulting difference greater than 0 implies that (1), new sources are being considered, (2), mean recurrence time estimates have decreased, (3), mean magnitude has increased, or (4), newly included attenuation models predict that the source is more likely to produce a larger ground motion. For example, if a site is on the hanging wall of thrust fault, median motion is higher for some attenuation models for a given $(R, M)$, a feature that is present in the 2002 hazard calculations but not in the 1996 calculations. If $\bar{\varepsilon}_{0}(' 02)-\bar{\varepsilon}_{0}$ ('96) is less than zero, one or more of the opposite conditions occurs. For example, at a few spots in Nevada, the blue zones along fault traces indicate that mean recurrence rate estimates of sources on those faults may have decreased (recurrence times increased) compared to 1996 estimates. Reddish colors associated with Nevada faults may indicate an increase in estimated recurrence rate. Green-colored locations in Figure 9 imply little change or canceling changes since 1996. One case of canceling changes is on the hanging wall of the Sierra Madre (SM) thrust fault, where a potential increase in hazard associated with new attenuation models is more than offset by a decrease in mean recurrence rate of earthquakes on the fault resulting from an increase in characteristic $\mathbf{M}$. When taken with other changes in the PSHA model, there is a net decrease in $1 \mathrm{~s}$ probabilistic motion (typically about $10 \%$ reduction) at such SM hanging wall sites in the 2002 update but essentially no change in $\bar{\varepsilon}_{0}$.

\section{California-Nevada Region Maps of Modal Source Parameters}

Figure 10 shows the modal-source magnitude for the 1-s SA with 2\% PE in 50 years for the states of California and Nevada. Modal-source magnitudes in this region range from about M6 mostly near Lake Mead to M9 in northern California. The white color in Figure 10 indicates where an M9 subduction event dominates the hazard, and shades of gray indicate where a large-magnitude San Andreas fault (SAF) source dominates the hazard. Seismic-wave attenuation models extend the modal influence of the megathrust source more than two degrees southeast of the Mendocino escarpment, the southern edge of the subducting oceanic plate. Similarly, an M8 source on the SAF contributes enough to seismic hazard at many sites in the Great Valley, almost $200 \mathrm{~km}$ east of fault trace, to be modal. The $2 \%$ in 50 year probabilisitic ground motions are relatively low in most of the Great Valley compared to other parts of western California. This implies that more local sources have low probability of occurrence compared to SAF main shocks. There is a paucity of recorded strong motion data at larger 
magnitudes and distances that might aid in validating large-M and large- $\mathrm{R}$ attenuation model predictions empirically.

In central California on a section of the SAF southeast of Monterey Bay, Figure 10 indicates that a M6.5 \pm source on the fault dominates the multi-segment rupture, higher magnitude, SAF scenarios. Relatively low-magnitude yet modal SAF events rupture either the creeping section or the Parkfield segment frequently. Compared to the multi-segment SAF sources, these single-segment ruptures have high recurrence rates or recurrence times on the order of a few dozen years, locally allowing the low-M to dominate the high-M SAF source.

Figure 11 shows the modal-source distance, or $\hat{R}$, for the 1-s SA with $2 \%$ PE in 50 years for the states of California and Nevada. The modal-source distance is typically less than $5 \mathrm{~km}$ at sites near active faults, shown as white lines in Figures $\underline{10}, \underline{11}$ and $\underline{12}$. Even when a site is directly over a fault, the modal-source distance can be more than $5 \mathrm{~km}$. This $\hat{R}>5 \mathrm{~km}$ phenomenon frequently occurs for less-active faults of Nevada and also occurs for a few faults in California. Sources inside the 0-to- $10 \mathrm{~km}$ annulus other than those on the fault may make a comparable contribution to the hazard as those on the fault, in which case the average distance in that bin can be greater than $5 \mathrm{~km}$. Very distant sources can also be modal in California. Greens and blues in the California $\hat{R}$ maps indicate that either Cascadia or SAF sources are the dominant hazard at distances of 100 to $200+\mathrm{km}$. Cascadia M9 sources also dominate the seismic hazard in parts of northern Nevada.

Figure 12 shows the modal-source $\varepsilon_{0}$ for the 1-s SA with 2\% PE in 50 years for the states of California and Nevada. The generally blue color of California's $2 \%$ in 50 year modal event $\varepsilon_{0}$ map (Figure 12 ) means that the $2 \% / 50 y e a r$ 1-s SA is about 1.8 times the median from the modal source, often called a "deterministic" motion. If the modal source occurs in Nevada, the yellow to orange to red colors of the map (Figure 12) indicate that the probabilistic 1-s SA is lower than the median ("deterministic") motion. In western California, the best example of a Quaternary fault that has low probabilistic SA associated with it is the longrecurrence-time Rinconada fault within the Salinian block southeast of Monterey Bay. The $2 \%$ in 50 year 1-s SA is considerably lower than the median for a characteristic earthquake on that fault. The rate of random seismicity determined from seismic network monitoring is low in the vicinity of the Rinconada fault (Hill et al, 1991), resulting in uniquely low, for western California, 1-s $\varepsilon_{0}$ for sites near that fault.

Figures $\underline{13}, \underline{14}$, and $\underline{15}$ show the modal-source $\hat{M}, \hat{R}$, and $\hat{\varepsilon}_{0}$, respectively, for the 0.2 -s SA with $2 \%$ PE in 50 years for California and Nevada. The modal $\mathrm{M}>7.7$ SAF source is far more restricted areally for the 5-hz SA than for 1-hz SA (c.f., Figure 10 and Figure 13 gray regions), except in the southern CaliforniaArizona border region, where it dominates seismic hazard sometimes at 
distances approaching $200 \mathrm{~km}$. The dominance of Cascadia M9 extends further into California's Great Valley for 5-hz SA than for 1-hz SA. This inversion of the usual distance effect occurs because subduction-source attenuation models attenuate higher frequency vibration less rapidly with distance than crustalsource attenuation models. The $\varepsilon_{0}$ map, Figure 15, indicates that in general, the $2 \%$ in 50 year probabilistic $5-\mathrm{hz}$ motion is about 1.4 to 1.8 times the modal-event median for sites west of the SAF, and is somewhat less for many sites east of the SAF. The $2 \%$ in 50 year $5 \mathrm{~Hz}$ motion for sites near the Great Valley blind thrust (GVBT) fault system is generally about median for rupture on those faults, except for sites on/near the northernmost GVBT, GV1. The probabilistic motion near GV1 is significantly less than median, due to its long (9600 year) mean recurrence time. Indeed GV1 has about the longest recurrence time of any California fault in the data base, but it is comparable to that of many Nevada faults. The vicinity of such faults is illuminated with red and brown colors in Figure 15. The Reno-Carson City corridor has higher probabilistic ground motion than most other parts of Nevada, mostly due to the relatively short recurrence time on the Carson Range (Mchar, 970 year) and other fault systems near that important urban area.

For California and Nevada, the modal source contribution factor or MCF is plotted in Figure 16. The 1-s SA MCF is shown in the lower left map of Figure 16, the 0.2-s SA MCF is shown in the upper left map, and PGA MCF is shown in the upper right map, all for the $2 \%$ PE in 50 years. Also, the 1-s SA MCF for the $10 \%$ $\mathrm{PE}$ in 50 years is shown in the lower right map of Figure 16. The MCF achieves local maxima at sites near several faults of western California, sometimes exceeding 0.7 ( $70 \%$ or more of the hazard). For any spectral period, the MCF decreases with PE. In Figure 16, this is more evident in Nevada than in California. The MCF for 1-s SA and $10 \%$ in 50 year PE is generally less than 0.05 ( $<5 \%$ of the hazard) for most sites in Nevada. The answer to the question, "how significant is the modal event?" at least with respect to the probabilistic definition, is that it is highly dependent on site location and on PE or exposure time. One can of course increase bin sizes to increase the MCF of the modal event. It is better, however, to recognize that a small MCF often indicates a multi-modal seismic-source distribution, and further investigation of non-modal sources might be worthwhile for many applications.

\section{Oregon-Washington Region Maps of Modal Source Parameters}

Various geophysical investigations in Washington and Oregon have yielded information on urban-area faults and models of Cascadia subduction that alter the USGS PSHA model significantly from that of 1996. Many of these reports are referenced in Frankel et al.,2002. Modal-event parameters assist in evaluating the relative importance of these sources to Pacific Northwest seismic hazard. Figure 17 shows the modal $\mathbf{M}$ for the $2 \%$ in 50 year PE 1-s SA for Washington, Oregon, and parts of Idaho. Fault traces are gray or white in this and subsequent 
maps. For 1-s SA, M9 megathrust is the dominant source through most of the Pacific NW, except for sites near the few characterized faults, principally, the Seattle and S. Whidbey Island faults in the Puget Sound area, and various faults in southern and eastern Oregon. Note that many of the Quaternary faults of western Oregon and eastern Washington do not provide modal events to the 1-s SA hazard at the $2 \%$ in 50 year PE, because of their very low recurrence rates compared to those of Cascadia sources.

Figure 18 shows the 1-s modal distance $(\hat{R})$ for the Pacific Northwest region for the $2 \%$ in 50 year PE. The irregular boundary between the eastern region where local seismicity dominates the hazard and the western region where Cascadia subduction dominates the hazard has the appearance of being a prominent feature of the PSHA model. In fact, this boundary is nothing more than the location where there is an exact balance between binned Cascadia hazard and binned local hazard, i.e., where the hazard distribution is bimodal (or perhaps multimodal).

Figure 19 shows the 1-s modal-event $\varepsilon_{0}$ for the region. In western Washington and Oregon the $2 \%$ in 50 year motion generally exceeds median motion for the modal source. In eastern Washington and Oregon, the probabilistic motion can be more than double the median motion from a Cascadia megathrust source. Characteristic earthquakes on some of the Quaternary faults of southeastern Washington and Oregon, or on the Seattle fault, for sites sufficiently near those faults, yield $2 \%$ in 50 year motions that can be below the median motion from those sources.

Figure 20 shows $\hat{R}$ for 5 -hz SA for the $2 \%$ in 50 year PE for Washington, Oregon, and parts of Idaho. A comparison of Figures $\underline{18}$ and $\underline{20}$ indicates that Cascadia subduction spatially dominates the seismic hazard to a lesser extent for 5-hz SA (or for PGA) than for 1-s SA. In eastern Oregon and Washington local random sources dominate the hazard, as well as sources on some, but not all, of the Quaternary faults in the 2002 model (shown as white lines). Note in Figure 20 the mixture of fault sources that do or do not dominate Cascadia subduction sources in western Oregon. This behavior is due to a wide range of estimated recurrence times for activity on these faults.

Local random sources dominate the 5-hz SA hazard at Bellingham, Washington, a change from the 1996 maps, where Cascadia subduction earthquakes were modeled closer to Bellingham, and dominated the hazard. The nearness to Bellingham of the boundary between local and M9 Cascadia sources implies that 5-hz SA (and PGA) has a multi-modal seismic hazard distribution at Bellingham, at least when data are binned as above. In fact the distribution of seismic sources is trimodal in Bellingham, with a third prominent peak associated with deep intraplate seismicity along with local and subduction sources, for higherfrequency SA. Deep intraplate sources like the destructive earthquakes of April 
1949, April 1965, and the Nisqually earthquake of February 2001 play a prominent role in PSHA at most sites in the vicinity of Puget Sound.

\section{A Closer Look at Seismic Hazard in Portland, Oregon}

Figure 21 examines the deaggregated seismic hazard source parameters for a site in Portland Oregon. Figure 21 is composed of four graphs. The bottom left graph of Figure 21 is a hazard curve for 1-s SA, where SA ranges from less than $0.05 \mathrm{~g}$ to about $0.8 \mathrm{~g}$. The vertical axis is mean rate of SA exceedances per year, according to the 2002 USGS PSHA model. The solid-line graph is the hazard curve, i.e., the curve resulting from all considered sources. The dash-line graph is the hazard contribution from the modal or most-likely source. In general, and in Portland, these curves are far apart at low SA levels, but converge for high SA levels. The upper left graph of Figure 21 is the graph of mean (solid-line) and modal (dash-line) distance as a function of 1-s SA at Portland. Note that mean distance is a smooth curve that decreases monotonically, while modal distance is a step function. At this site, with coordinates $45.5^{\circ} \mathrm{N}, 122.65^{\circ} \mathrm{W}$., the modal source distance is initially about $140 \mathrm{~km}$ for low SA, and changes significantly twice. The upper right graph of Figure 21 is mean and modal $\mathbf{M}$ for the site, 1-s SA. For low SA, the modal $\mathbf{M}$ is 8.3 , then jumps to 9.0 , then decreases to about 6.7. The first two modal $\mathbf{M}$ values correspond to Cascadia subduction, either a partial rupture, or a nearly entire oceanic plate megathrust, from the Mendocino escarpment to Vancouver Island. The final modal $\mathbf{M}$ corresponds to rupture on the Portland Hills fault system. The squares on the graphs are located at the $2 \%$ in 50 year ground motion, i.e., where the mean rate of exceedance is 0.000404 . The modal $\mathbf{M}$ at this PE corresponds to a characteristic source on the Portland Hills fault.

The lower right graph of Figure 21 is mean and modal $\varepsilon_{0}$ for 1-s SA at Portland. Note that mean $\varepsilon_{0}$ increases monotonically with $\mathrm{SA}$, but modal $\varepsilon_{0}$ has a sawtooth pattern, dropping sharply at each SA-value where the modal source (R,M) changes significantly, then ramping up ( $\approx$ linearly with log $S A$ ). For the $2 \%$ in 50 year 1-s SA, the $\varepsilon_{0}$ corresponding to the Portland Hills modal source is about 0.5 . Note that $\varepsilon_{0}$ for Cascadia sources in Portland is much higher, $\approx 1$ for the $\mathbf{M} 9$ source, at that PE. The sawtooth behavior of $\hat{\varepsilon}_{0}$ with sa is an important feature to consider when considering maps of $\hat{\varepsilon}_{0}$ and how they might be applied in specific contexts. For example, a low $\hat{\varepsilon}_{0}$ does not imply that non-modal sources also have low $\varepsilon_{0}$.

With respect to the relationship between $\mathrm{SA}_{0}$ and $\hat{\varepsilon}_{0}$ for this example, the 1-s $\mathrm{SA}_{0}$ for the $2 \%$ in 50 year PE at this site in Portland is $0.375 \mathrm{~g} . \hat{\varepsilon}_{0}=-0.567$. Modal $(R, M)$ is $(3.06 \mathrm{~km}, 6.76)$. The Portland Hills fault is a reverse fault that dips southwest, and the site is east of the fault. Using the Campbell and Bozorgnia (C\&B, 2003) attenuation model, $0.375 \mathrm{~g}$ is less than the median motion for a 
reverse-slip earthquake with the stated $(R, M)$. Specifically, $\varepsilon_{0}$ from $C \& B$ is -0.40 given that ground motion and $(\mathrm{R}, \mathrm{M})$ pair. Note that $\varepsilon_{0 C \& B}$ is close to $\hat{\varepsilon}_{0}$. However, mean $\left(\mathrm{R}, \mathrm{M}, \varepsilon_{0}\right)$ for that PE and ground motion is $(49.7 \mathrm{~km}, 7.5,0.76) . \varepsilon_{0}=2.56$ for that R,M pair using the Campbell and Bozorgnia relation. Portland is one of many cities where $\varepsilon_{0}$ computed for the mean $(R, M)$ and any utilized attenuation model is substantially larger than $\bar{\varepsilon}_{0}$. In other words, you will not even approximately recover the probabilistic ground motion by the quantity $\exp \left(\mu+\bar{\varepsilon}_{0} \sigma\right)$ where $\mu$ is determined using the mean (R,M) (Equation 3 above) but you will approximately recover the probabilistic ground motion by the quantity $\exp \left(\mu+\hat{\varepsilon}_{0} \sigma\right)$ where $\mu$ is determined using the modal $(\mathrm{R}, \mathrm{M})$ and a dominant attenuation model (Equation 2 above). One point of this argument is that efforts to generate seismograms from scenario earthquakes that have the mean magnitude and distance and which are scaled by the mean $\varepsilon_{0}$ may yield results whose amplitudes are significantly lower than the probabilistic SA.

\section{Maps of Modal Source Parameters in the Intermountain Seismic Belt}

The rapidly growing Salt Lake City-Ogden urban corridor is near the Wasatch front fault system, which has long been known to be a substantial earthquake threat. Return times for characteristic earthquakes on these faults is 1500 to 2000 years. Some of the largest conterminous U.S. earthquakes in the latter half of the twentieth century occurred in the ISB region, although not on the Wasatch front. These include Hebgen Lake, an M7.3 earthquake that occurred in 1959, and Borah Peak, an M6.9 earthquake that occurred in 1983.

Figure 22 shows the 1-s SA for the $2 \%$ in 50 year PE for the ISB region. The left side shows the update-map SA level, in percent $g$. The 1-s SA can be in excess of $60 \% \mathrm{~g}$ for sites near the Wasatch frontal fault system and near faults in western Wyoming. The right side shows the change in SA, i.e., the 1-s SA of the 2002 map minus that of the 1996 map, in the same units. This map shows that there has generally been less than $10 \% \mathrm{~g}$ increase or decrease in 1-s SA from 1996 to 2002. One of the largest changes occurs for sites near the Joes Valley fault system, designated JV in Figure 22. For sites near JV, the increase in 1-s SA can exceed $25 \% \mathrm{~g}$. The east-dipping JV fault has a relatively high slip rate, 0.75 $\mathrm{mm} /$ year, which has increased significantly from that used in the 1996 PSHA.

The broad regional increase on the order of 5 to $10 \% g$ in the 1-s SA for 2002 compared to 1996, evident in Figure 22, results primarily from newly included attenuation models. The 0.2-s SA in the ISB region (not shown) generally decreases compared to that of 1996, except near a few faults on which rate estimates have increased. The regional decrease in 0.2-s SA is due, again, to new attenuation models, most notably, Spudich et al (1999). Sufficiently large increases in random seismicity rate estimates (a-grid values) can increase the 0.2-s SA from that of 1996, more than offsetting the lowering effect of new 
attenuation models. Pocatello, Idaho, is one city where local a-grid increases result in about a 5 to $10 \% \mathrm{~g}$ increase in 0.2-s SA. Changes in a-grid values have little influence on the 1-s motion, however, at least at the $2 \%$ in 50 year PE.

Figure 23 shows the 1-s modal-source magnitude, or $\hat{M}$, on the left-side map and modal-source distance, or $\hat{R}$, on the right side, for the 2002 update PSHA and the $2 \%$ in 50 year PE. $\hat{M}$ is generally about M7.1 in the Salt Lake City-Ogden urban corridor. At sites near the Provo section of the Wasatch fault system, the modal-source $\mathbf{M}$ can exceed 7.3. For sites in this urban area, $\hat{R}$ is often less than $5 \mathrm{~km}$. The PSHA crustal attenuation model changes from a WUS high attenuation to a CEUS low attenuation in the region shown in Figures $\underline{22}$ and 23 . The approximate longitude where this change occurs at these latitudes is about $109^{\circ}$ to $110^{\circ} \mathrm{W}$. East of this transition, relatively distant random seismicity can dominate the hazard, resulting in $\hat{R}>150 \mathrm{~km}$, indicated with light to dark blue colors in the right-side map of Figure 23. West of this transition longitude, relatively close random seismicity, $\hat{R}$ in the 20 to $30 \mathrm{~km}$ range, indicated with an orange color, can dominate the hazard, at least where no mapped Quaternary faults are located in the vicinity of the site.

\section{Central and Eastern U.S. Modal Source Parameter Maps}

Figure 24 shows 1-s and 0.2-s SA modal-source magnitude, or $\hat{M}$, for the $2 \%$ in 50 year PE for the CEUS. As was the case in 1996, the NMSZ mainshock often dominates the 1-s CEUS seismic hazard, to the maximum considered source-toreceiver distance of $1000 \mathrm{~km}$. However, modal M for NMSZ mainshocks is now 7.7 rather than 8.0, and there is a distribution of other possible magnitudes in the hazard model. The NMSZ source is located on one of the three S-shaped strands that cross the Mississippi River at about 36 to $36.5^{\circ} \mathrm{N}$, shown as white lines.

The other major seismic hazard source in the CEUS is a mainshock in the Coastal Plain of South Carolina, similar to the 1886 earthquake. The modalsource $\mathbf{M}$ is 7.3 , as it was in 1996 , although in 2002 , there is a distribution on possible magnitudes from 6.8 to 7.5 . M7 sources on the Meers fault of southwest Oklahoma are modal through much of Oklahoma and Texas, especially for the 0.2-s SA. The Meers fault, shown as a faint white line, is the only Quaternary fault with known location in the region mapped in Figure 24 that is recognized as a fault source in the 2002 update (same as in 1996). A few other possible CEUS tectonic Quaternary faults are discussed in Crone and Wheeler (2000).

According to the hazard depicted in Figure 24, several pockets of local seismicity with mean $\mathbf{M}<5$ dominate the 0.2 -s hazard from eastern Tennessee north to Ohio and northeast to Maine, although none of these low-M sources dominates the 1-s hazard anywhere in the CEUS. Another prominent source zone on both 
1-s and 0.2-s $\hat{M}$ maps is the Charlevoix-St. Lawrence River region north of Maine. At Charlevoix, the concentric circles of different $\mathbf{M}$ modal sources indicate that when using a $\mathrm{dM}=0.2$ bin size, sources having a variety of magnitudes from about 6.8 to 7.3 may contribute almost equally to the site's hazard.

Figure 25 shows 1-s and 0.2-s SA modal-source distance, or $\hat{R}$, for the $2 \%$ in 50 year PE for the CEUS. Figure 25 again shows that NMSZ mainshocks can dominate the 1-s hazard out to $1000 \mathrm{~km}$ in Texas, Minnesota, Wisconsin, and several other states. The darker gray regions beyond the 1000-km limit of NMSZ hazard indicate that more than $500-\mathrm{km}$-distant random seismicity dominates the hazard at many locations in North Dakota, Minnesota, Pennsylvania, Florida, and several other states. Bear in mind that this result is a function of the large annulus, R from $500 \mathrm{~km}$ to $1000 \mathrm{~km}$, used to evaluate the relative importance of distant sources to the seismic hazard when preparing these maps. The next largest R-bin, from 300 to $500 \mathrm{~km}$ radial distance, also provides a modal source to many locations in the CEUS. Figure 25 shows that the modal distance to the Charleston source can be quite small, at some locations less than $10 \mathrm{~km}$, for sites in the "narrow" zone discussed in greater detail below and in Frankel et al (2002).

Many of the red spots in the 0.2-s CEUS $\hat{R}$ map of Figure 25 are the result of determining an a-value from one or two earthquakes in the CEUS earthquake data-base. One such location is the Keweenaw peninsula of northern Michigan, whose 0.2-s SA level has been slightly elevated by an earthquake with epicenter under Lake Superior.

The left and right sides of Figure 26 show the modal-source $\varepsilon_{0}$ for the CEUS for 1$s$ and 0.2 -s SA with $2 \%$ in 50 year PE. The 1-s map shows that for much of the CEUS the $2 \%$ in 50 year probabilistic motion is about 1.8 times the median motion from the modal or most likely source. However, at some CEUS sites the $2 \% / 50$ year motion is somewhat less than the median ground motion from the modal source. Such site locations are indicated with yellow, orange, red, and brown colors in Figure 26. The 0.2-s map also shows large regions for which the $2 \%$ in 50 year motion is greater than the modal-source median motion. Sites in the western Long Island/eastern New Jersey region, for example, have 5-hz probabilistic motion about 1.2 to 1.4 times the median motion from the modal source. Exceptional regions are found near possible locations of the Charleston, S.C., mainshock, and the Meers, Oklahoma, fault. At these locations the probabilistic motion can be significantly lower than the median of the characteristic earthquake.

Figure 27 is a map of $\hat{M}$ for 2-s SA (left side) and $0.1 \mathrm{~s} \mathrm{SA} \mathrm{(right} \mathrm{side)} \mathrm{for} \mathrm{the}$ CEUS and the $2 \%$ in 50 year PE. Comparing Figure 27 with Figure 24, we see that the 2-s $\hat{M}$ is usually the same as or very similar to the 1 -s $\hat{M}$. A Meers fault earthquake dominates the 1-s hazard over a broader region than the 2-s hazard. This is due to the fact that the 2-s motion from the NMSZ mainshock is less 
rapidly attenuated with distance than the 1-s motion. The local source contributes relatively more ground-motion exceedances compared to the regional source for shorter-period motion, broadening the modal influence of the nearer source in southwestern Oklahoma and parts of Texas. The 10-hz map shows even more clearly the dominance by local sources when compared to the 5-hz map. Whereas Meers-fault M7 characteristic earthquakes supplant NMSZ M7.7 characteristic earthquakes in much of Oklahoma for 1-s SA compared to 2-s SA, local sources in the M4.5 to 5 range supplant Meers $\mathbf{M} 7$ sources in the same region for 10-hz SA compared to 5-hz SA. For example, the blue spot $200 \mathrm{~km}$ northeast of the Meers fault on the right-side map of Figure 27 is the result of a locally elevated seismicity rate, partly driven by a $m_{b\llcorner g} 5.1$ earthquake on April 9 , 1952. Similar hierarchies of seismic hazard from local, more regional, more distant sources can be found in many other states of the CEUS. In other words, there are many CEUS sites for which three or more distinct nearly modal bins in the magnitude, distance distribution will exist for higher frequency probabilistic motion.

Figure 28 shows modal-source $\varepsilon_{0}\left(\hat{\varepsilon}_{0}\right)$ for the CEUS PGA at $2 \%$ in 50 year PE, left side, and $10 \% \mathrm{PE}$ in 50 years, right side. $\hat{\varepsilon}_{0}$ can be higher for the $10 \%$ in 50 year motion than for the $2 \%$ in 50 year motion, but this cannot occur for $\bar{\varepsilon}_{0} . \hat{\varepsilon}_{0}$ drops when the modal-source $\mathbf{M}$ or $\mathbf{R}$ changes over some considered range of probabilities. Recall, in the Portland, Oregon seismic hazard section above, two significant changes to modal $(R, M)$ occur, one at a ground motion between the $10 \%$ in 50 year and the $2 \%$ in 50 year motions. These PGA $\varepsilon_{0}$ map comparisons are presented to remind us that modal event $\mathbf{R}, \mathbf{M}$, and $\varepsilon_{0}$ should be considered as a single vector entity rather than separately, as scalar statistics.

\section{Central and Eastern U.S. Mean Source Parameter Maps}

Figure 29 shows the mean-source magnitude, $\bar{M}$, units Mw, for the CEUS and for 1-s and 0.2 -s SA, and the $2 \%$ PE in 50 years. $\bar{M}$ for 1-s SA, shown on the left map, is usually less than 6.9 but greater than 6.5 except in the lowest-hazard regions. $\bar{M}$ rises in the South Carolina coastal plain to about 7.3, and rises in the NMSZ to about 7.7. $\bar{M}$ for 0.2-s SA, shown on the right map, is lower for the most part, less than 6 in many parts of the map. In the central part of the NMSZ, $\bar{M}$ rises to about 7.7. In the northeast US, the 0.2 -s SA $\bar{M}$ is in the 6 to 6.5 range for the most part.

Figure 30 shows the mean source distance, or $\bar{R}$, in $\mathrm{km}$, for the CEUS and for 1-s and 0.2-s spectral periods. The mean distance from CEUS sites to CEUS sources is generally greater than $\bar{R}$ in the WUS, and the 1-s mean distance (left side) is generally significantly greater than the 0.2-s SA mean distance. The former fact is primarily due to the lower rate of attenuation of seismic waves in the CEUS crust compared to WUS crust. The changeover longitude is modeled 
as a sharp boundary - one which varies with latitude - but a more gradual transition is probably more likely. Epicenter concentrations that have produced higher than average a-values show up fairly well in the 0.2-s SA $\bar{M}$ map, but they are generally not visible at intermediate to long period SA. The most prominent exception to this observation is the Charlevoix- St Lawrence River seismicity, which is important to local and some regional seismic hazard at all spectral periods.

Figure 31 shows CEUS-region maps of the mean-source $\varepsilon_{0}$, the left map for the 1 -s and the right map for the 0.2-s spectral periods, for the $2 \%$ in 50 year PE. These maps show that over broad regions the $2 \%$ in 50 year motion is greater than median motion from the mathematically defined but otherwise nebulous "mean" source, even for sites near the NMSZ, shown as three white S-shaped curves. The only geographically extensive region of Figure 31 where $2 \%$ in 50 year motion does not approach the median motion from the mean source is in the vicinity of the Meers fault of southwest Oklahoma, shown as a white line in Figure 31.

\section{New Madrid Seismic Zone Modal Source Parameters}

The NMSZ has the highest probabilistic ground motions in the CEUS. The 18111812 mainshocks have estimated $\mathbf{M}$ ranging from 7 to 8 and greater. In the 1996 PSHA maps, the NMSZ characteristic sources were modeled with $\mathbf{M}=8$. In the 2002 maps, the characteristic source is modeled with a distribution of $\mathbf{M}$ from 7.3 to 8 . The modal magnitude tends to be $\mathbf{M} 7.7$ for a wide range of spectral periods and return times for most sites in the vicinity of the NMSZ. In 1996, the estimated mean recurrence time of this source was 1000 years. In 2002 the estimated mean recurrence time is 500 years (Frankel et al., 2002), based on recent research findings of paleoseismologists. The simultaneous lowering of $\mathbf{M}$ and raising of recurrence rate produce offsetting effects on probabilistic motion for the $2 \%$ in 50 year PE. The higher rate does however increase the $10 \%$ in 50 year PE SA levels considerably from those of 1996.

Figure 32 exhibits some details of the new PSHA model for the NMSZ region and the 5-hz SA, for the $2 \%$ in 50 year PE. The upper left map of Figure 32 is the 5-hz SA in percent $g$. The white lines represent the range of locations used to model the NMSZ fault(s). The central fault trace follows the epicenter trend of monitored microseismicity (Frankel et al., 2002). The probabilistic motion within 10 to $20 \mathrm{~km}$ of the central trace exceeds $300 \% \mathrm{~g}$ and the motion within a few $\mathrm{km}$ of the eastern and western traces exceeds $250 \% \mathrm{~g}$. At a distance of $150 \mathrm{~km}$, the $5-\mathrm{hz}$ probabilistic SA has dropped to about $40 \% \mathrm{~g}$, an 8 -fold decrease compared to the maximum on the central trace. For rock sites in Memphis, Tennessee, the probabilistic motion exceeds $110 \% \mathrm{~g}$. 
The upper right map of Figure 32 compares the probabilistic 5-hz SA for 2002 with that of the 1996 maps by plotting their ratio, SA(2002)/SA(1996) (1 represents no change). In general there is a slight increase in g.m. for 2002, rarely exceeding $30 \% g$ in the region shown. At most locations in the mapped region, the increase is less than $10 \% \mathrm{~g}$. The gray fault traces in this figure are at the locations of the three NMSZ faults in the 1996 PSHA, while the white fault traces correspond to the 2002 PSHA. The change in location of the eastern trace as well as the greater weight assigned to the middle trace in the 2002 model explain the increase in $5-\mathrm{Hz}$ SA shown in this figure, which in two spots exceeds $20 \%$.

The modal-event magnitude everywhere in the mapped region of Figure 32 is M7.7. The lower left map of Figure 32 is the modal-event $\varepsilon_{0}$ for the 5-hz SA and the $2 \%$ in 50 year PE. The three NMSZ possible fault locations are again shown as white lines. At most locations $\varepsilon_{0}$ is greater than 0 , meaning that the $2 \%$ in 50 year motion exceeds median motion from potential NMSZ M7.7 mainshocks. There are yellow bands just outside the eastern and western traces, indicating locations where modal-source $\varepsilon_{0}$ is slightly less than zero.

The lower right map of Figure 32 is modal-source distance $(\hat{R})$ for the 5-hz SA and the $2 \%$ in 50 year PE. This map indicates that $\hat{R}$ can be as low as $10 \mathrm{~km}$ for sites near the central NMSZ fault trace (the central white line). The NMSZ faults are modeled such that the top or shallowest edge is at $10 \mathrm{~km}$ depth. This fact coupled with the use of a Rrup-type distance metric yields a $10 \mathrm{~km}$ modal-source distance for sites such as Cairo Illinois over or almost over the central fault trace. Sites in Memphis are about 30 to $40 \mathrm{~km}$ from the nearest location on the eastern trace shown. M7.7 sources on the eastern trace are modal for sites in Memphis, even though the eastern and western fault sources are given only $25 \%$ weight each in the PSHA model of Frankel et al (2002).

\section{South Carolina Modal Source Parameters}

Parts of South Carolina have relatively high probabilistic ground motion, second only to that at sites near the NMSZ in the CEUS. Large probabilistic motion results from the relatively short mean recurrence time of the 1886 -like characteristic earthquake, 550 years in the 2002 PSHA model. Owing to the low rate of seismic attenuation in the CEUS, the influence on probabilistic ground motion of the Charleston source is great throughout South Carolina and other southeast U.S. states. With respect to impact on PSHA maps, the main new feature of the 2002 update in the vicinity of the South Carolina coastal plain is the inclusion - with $50 \%$ weight - of a narrow zone of Charleston-like seismic sources, areally the same as the south Zone of River Anomalies, or ZRA of Marple and Talwani (2000). The updated hazard model mean recurrence time of the Charleston-like source is shorter than the 650-year estimate used in the 1996 model calculations, also resulting in an increase in probabilistic SA and PGA. 
Figure 33 is a four-map examination of the new seismic hazard for 0.2-s SA, and $2 \%$ in 50 year PE in South Carolina and vicinity. The upper left map is the $5-\mathrm{Hz}$ probabilistic SA, which can exceed $200 \% \mathrm{~g}$ in the ZRA (the "narrow zone"). The upper right map is the ratio $S A(2002) / S A(1996)$. The most notable feature is the increase in $5-\mathrm{Hz}$ SA in the narrow zone, a change of up to $40 \%$, or in units, $60 \%$ $g$ to $80 \% g$. This map also shows that in spite of the shorter Charleston mainshock recurrence time, several factors more than counterbalance the rate effect to produce a net decrease in $5 \mathrm{~Hz}$ probabilistic motion by a small amount (generally 0 to $10 \% \mathrm{~g}$ ) in most of the state away from the ZRA. These factors include (1), a more comprehensive set of ground-motion attenuation models, (2), the greater average distance to the Charleston source for sites sufficiently far from the ZRA, and (3), truncation of sa at $\mu+3 \sigma$.

In the 2002 update, there is a distribution of magnitude (i.e., logic tree) for Charleston sources, ranging from M6.8 to M7.5, discussed in Frankel et al (2002), whereas in the 1996 PSHA, Charleston-source $\mathbf{M}$ was fixed at 7.3. It is not transparent whether the $2002 \mathrm{M}$ distribution increases or decreases probabilistic motion relative to the fixed-M model. Analysis indicates that for the $2 \%$ in 50 year PE, the distribution of $\mathbf{M}$ with weights as defined in the 2002 update decreases probabilistic SA and PGA by up to a few percent compared to using the fixed-M Charleston source model, for sites throughout South Carolina and vicinity. The decrease is greatest in the Coastal Plain.

The lower left map of Figure 33 is 5-hz SA modal-source magnitude, or $\hat{M}$, for the 2002 PSHA model. $\hat{M}$ is M7.3 to M7.36 in most of the state. $\hat{M}>7.3$ results from the addition to the modal bin of random seismicity sources with $\mathbf{M}$ as great as 7.46 in the extended margin (Frankel et al., 2002). M7.5 in the extended margin is the same Mmax as that assumed for the 1996 hazard calculations; however, in the stable craton Mmax was raised in the 2002 calculations, from 6.5 to 7.0. Only the northwest corner of South Carolina has a substantially lower $\hat{M}$ than M7.3, due to the influence of the eastern Tennessee seismic zone (ETSZ), which is the most active region, seismically, of all of the Appalachian Mountains. Clemson, S.C., is located in a region where the probabilistic source distribution is bimodal, with $(R, M)$ peaks associated with an 1886-like M7.3 earthquake with epicenter in the Atlantic Coastal Plain and with an ETSZ M5 \pm earthquake.

The lower right map of Figure 33 is the 5-hz SA modal-source distance, or $\hat{R}$, in $\mathrm{km}$, for South Carolina and the $2 \%$ in 50 year PE. $\hat{R}$, i.e., the distance to the most likely source, is between 5 and $10 \mathrm{~km}$ in a cigar-shaped region corresponding to, but lengthier than, the ZRA. Finite-length sources with strike parallel to the main axis of the ZRA with notional fault centers in the ZRA can extend outside the ZRA, whose boundaries are shown in Figure 3 of Frankel et al. (2002). These finite notional sources are the reason for the long zone where $\hat{R}$ is less than $10 \mathrm{~km}$. $\hat{R}$ for sites in Charleston, S.C. is about 15 to $20 \mathrm{~km}$. 


\section{Summary}

This report exhibits maps of modal and mean source parameters for the $2 \%$ in 50 year PE according to the new USGS seismic hazard model documented in Frankel et al. (2002). These maps cover the conterminous U.S. More detailed maps of a few sub-regions with higher than average probabilistic ground motion are also presented. In a few cases, the $10 \%$ in 50 year modal-event maps have been shown alongside the $2 \%$ in 50 year maps for comparison.

At one city, Portland, Oregon, graphs of mean and modal $\mathrm{R}, \mathrm{M}$, and $\varepsilon_{0}$ are presented with the probabilistic seismic hazard curve for 1-s SA to demonstrate how modal source parameters vary discontinuously with increasing ground motion, while mean source parameters vary smoothly with ground motion. In Portland, the modal source may be a Cascadia subduction earthquake or rupture on a local fault, depending on exposure time, or level of ground motion. At many locations, a similar variation in the dominant source with exposure time may be expected. Typically, a more frequently occurring source at a more regional distance dominates the hazard (i.e., is modal) for low SA levels, and a closer, but less frequent (longer mean recurrence time) source dominates the hazard at higher SA levels.

\section{Conclusions and Discussion}

Sensitivity studies about features of regionally dominant sources, such as that of Cramer (2001), suggest that such analysis can provide useful information to those who make decisions on research priorities and hazard mitigation strategies. That is, increments in knowledge and understanding of some features of such dominant sources, such as fault location, recurrence rate, and so on, may have greater impact on estimates of probabilistic ground motions than other increments, and may therefore merit more research effort. Deaggregation analysis can be used to determine these sources, the degree of dominance, for example MCF maps like Figure 16, and the basis for their dominance, including the ground-motion prediction equations that may be pivotal in making such a determination.

The 2002 USGS PSHA update often yields the same or similar modal sources as the 1996 USGS PSHA. This may be verified by comparing the maps of this report with those of Harmsen et al (1999) and Harmsen and Frankel (2001). Many hazard details have changed, some of which are visible on nation-scale maps, but most of which are best appreciated by performing site-specific seismic hazard deaggregation. At the 2002 interactive deaggregation web site, http://eqint.cr.usgs.gov/eq/html/deaggint2002.html, the user may perform these 
deaggregations and learn about new and modified sources. Several new or previously unused attenuation models have also been included in the 2002 USGS PSHA. Although their effects are in the results, we have not attempted in this report to deaggregate hazard from different attenuation models.

PSHA maps may change significantly when additional research and understanding indicate the need to modify strong-motion attenuation models and/or seismic sources, e.g., their location, their size, and their likelihood of occurring in a random or specific future period. The most obvious way to document the impact of these changes is to present maps of differences or ratios of probabilistic motion, as has been done in s. 22, 32, and 33 of this report. The change in mean $\varepsilon_{0}$, such as that presented in Figure 9, is a less obvious indicator of changes in PSHA map input data. However, maps such as Figure 9 may complement other comparison maps, such as ratios of $\bar{R}$, differences of $\bar{M}$, or other contrasts that one might consider when trying to evaluate potential impact on seismic safety decisions of significant changes in our understanding of seismic hazard in the USA. Ideally, deaggregation products will be considered when incorporating an evolving understanding of the seismic hazard into the design and retrofit decision process. Considering maps such as Figure 9 that compare "old" and "new" probabilistic source parameters provides a more comprehensive basis of background information for making informed decisions than just considering differences in probabilistic motion that result from updates of the USGS or any other PSHA.

One purpose of deaggregation analysis is to find plausible $(R, M)$ pairs from which to choose accelerograms, $A(t)$, for input to seismic design programs for structural response. If one chooses $A(t)$ corresponding to the mean $(R, M)$, at many sites and for the $2 \%$ in 50 year (or other) PE, the accelerograms will tend to yield spectral accelerations that are significantly lower than the probabilistic spectral acceleration, as in Eqn. (5) above. Therefore, it is frequently necessary to scale seismograms to the probabilistic motion.

While the mean is an important parameter for characterizing a statistical distribution, its usefulness has been challenged in the seismic-resistant design application for another reason. For sites that have multimodal hazard distributions, the mean magnitude, distance pair can represent a source that has little or no probability of occurrence. For example, at Portland Oregon, the mean $(\mathrm{M}, \mathrm{R})$ for 1-s SA and the $2 \%$ in 50 year PE is $(7.5,50 \mathrm{~km})$, an "amalgamation" of local sources at lower magnitudes and much more distant subduction sources having M8.3 or M9. This multi-modal feature could conceivably result in an undesirable choice of earthquake $A(t)$ to resist if design decisions are tied very closely to resisting certain $(M, R)$ pairs, such as the mean $(M, R)$, but not others for a given $\mathrm{SA}$ and $\mathrm{PE}$. The maps of mean magnitude, distance, and $\varepsilon_{0}$ presented here are intended to convey information about the distribution of probabilistic seismic sources rather than to provide prescriptions or suggestions for seismic sources to use in building design or retrofit projects. 
The information of deaggregation analysis can and perhaps should be considered in a complex seismic-resistant design decision-making environment.

\section{Acknowledgements:}

This document was reviewed by E.V. Leyendecker, U.S.G.S. Nancy Dickman helped prepare the web-viewable version of the document. Most figures were prepared from GMT by Wessel and Smith.

\section{References Cited}

Abrahamson, N. A. and K. M. Shedlock, 1997. Some comparisons between recent ground-motion relations, Seism. Res. Lett., 68, pp 9-23.

Abrahamson, N. A. and W. J. Silva, 1997. Empirical response spectral attenuation relations for shallow crustal earthquakes, Seism. Res. Lett., 68, pp 94-127.

Campbell, K.W., and Y. Bozorgnia, 2003. Updated near-source ground motion (attenuation) relations for the horizontal and vertical components of peak ground acceleration and acceleration response spectra, . Bull. Seism. Soc. Am. , 93, 314-331.

Cramer, C. H., 2001. The New Madrid seismic zone: Capturing variability in seismic hazard analysis. Seism. Res. Lett., 72, 664-672.

Crone, T. and R. Wheeler, 2000. Data for Quaternary faults, liquefaction features, and possible tectonic features east of the Rocky Mountains. USGS OFR 2000-0260, at URL http://pubs.usgs.gov/of/2002/ofr-00-0260/.

Frankel, A., C. Mueller, T. Barnhard, D. Perkins, E. Leyendecker, N. Dickman, S. Hanson, and M. Hopper (1996), National seismic-hazard maps: documentation, June 1996, U.S. Geol. Surv. Open-File Rept., 96-532, 110 pp.

Frankel, Arthur D., Mark D. Petersen, Charles S. Mueller, Kathleen M. Haller, Russell L. Wheeler, E.V. Leyendecker, Robert L. Wesson, Stephen C. 
Harmsen, Chris H. Cramer, David M. Perkins, and Kenneth S. Rukstales (2002). Documentation for the 2002 Update of the National Seismic Hazard Maps, U.S. Geological Survey Open-File Report 02-420.

Harmsen, S., 2001. Mean and modal epsilon in the deaggregation of probabilistic ground motion, Bull. Seism. Soc. Am. 91, 1537-1552.

Harmsen, S., D. Perkins, and A. Frankel, 1999. Deaggregation of Probabilistic Ground Motions in the Central and Eastern United States, Bull. Seism. Soc. Am. 89, 1-13.

Harmsen, S. and A. Frankel, 2001. Geographic deaggregation of seismic hazard in the United States. Bull. Seism. Soc. Am. 91, 13-26.

Hill, D.P., J.P. Eaton, W.L. Ellsworth, R.S. Cockerham, F.W. Lester, and E.J. Corbett, 1991. The seismotectonic fabric of central California, ch. 8 of Neotectonics of North America: Decade Map Volume.Geol. Soc Am., Boulder, CO. pp. 107-132.

Hudson, D. E., 1979. Reading and Interpreting Strong Motion Accelerograms, Earthquake Engineering Research Institute, Berkeley, CA. 112 p.

Marple, R. T. and P. Talwani, 2000. Evidence for a buried fault system in the Coastal Plain of the Carolinas and Virginia - Implication for neotectonics in the southeastern United States, Geol. Soc. Am. Bull.,112, p. 200-220.

McGuire, Robin K. (1995). Probabilistic seismic hazard analysis and design earthquakes: closing the loop. Bull. Seism. Soc. Am., 85, 1275-1284.

Mueller, C. S., A. D. Frankel, M. D. Petersen, and E. V. Leyendecker, 2003. Probabilistic Seismic hazard maps for Puerto Rico and the U.S. Virgin Islands, Seism. Res. Lett. 74, p. 207.

Sadigh, K., C.-Y. Chang, J. A. Egan, F. Makdisi, and R.R. Youngs, 1997. Attenuation relationships for shallow crustal earthquakes based on California strong-motion data, Seism. Res. Lett., 68, 180-189. 
Spudich, P., W.B. Joyner, A.G. Lindh, D.M. Boore, B.M. Margaris, and J.B.

Fletcher, 1999. SEA99: A revised ground motion prediction relation for use in extensional tectonic regimes, Bull. Seism. Soc. Am., 89, 1156-1170.

Youngs, R.R., S.-J. Chiou, W.J. Silva and J.R. Humphrey, 1997. Strong groundmotion relationships for subduction zone earthquakes, Seism. Res. Lett., 68, pp. 58-73.

\section{Figures}

Figure 1. Maps of modal-event magnitude (or Mhat) in the western U.S. for the PSHA model of Frankel et al. (2002), for the $2 \%$ in 50 year probability of exceedance. Left side, for 1.0-s spectral acceleration. Right side, for 0.2-s, or 5$\mathrm{Hz}$, spectral acceleration.

Figure 2. Maps of modal-event distance (or Rhat) in the western U.S. for the PSHA model of Frankel et al. (2002), for the $2 \%$ in 50 year probability of exceedance. Left side, for 1.0-s spectral acceleration. Right side, for 0.2-s, or 5$\mathrm{Hz}$, spectral acceleration.

Figure 3. Maps of modal-event $\mathbf{E}_{0}$ (or epsilon-sub-zero) in the western U.S. for the PSHA model of Frankel et al. (2002), for the $2 \%$ in 50 year probability of exceedance. Left side, for 1.0-s spectral acceleration. Right side, for 0.2-s, or 5$\mathrm{Hz}$, spectral acceleration.

Figure 4. Maps of modal-event magnitude in the western U.S. for the PSHA model of Frankel et al. (2002), for the $2 \%$ in 50 year probability of exceedance. Left side, for 2.0-s spectral acceleration. Right side, for $0.1-\mathrm{s}$, or $10-\mathrm{Hz}$, spectral acceleration.

Figure 5. Maps of modal-event magnitude in the western U.S. for the PSHA model of Frankel et al. (2002), for peak horizontal ground acceleration, or PGA. Left side, for the $2 \%$ in 50 year probability of exceedance. Right side, for the $10 \%$ in 50 year probability of exceedance.

Figure 6. Maps of modal-event distance in the western U.S. for the PSHA model of Frankel et al. (2002), for peak horizontal ground acceleration, or PGA. Left side, for the $2 \%$ in 50 year probability of exceedance. Right side, for the $10 \%$ in 50 year probability of exceedance.

Figure 7. Maps of mean-event magnitude (or Mbar) in the western U.S. for the PSHA model of Frankel et al. (2002), for the $2 \%$ in 50 year probability of 
exceedance. Left side, for 1.0-s spectral acceleration. Right side, for $0.2-\mathrm{s}$, or 5$\mathrm{Hz}$, spectral acceleration.

Figure 8. Maps of mean-event distance (or Rbar) in the western U.S. for the PSHA model of Frankel et al. (2002), for the $2 \%$ in 50 year probability of exceedance. Left side, for 1.0-s spectral acceleration. Right side, for 0.2-s, or 5$\mathrm{Hz}$, spectral acceleration.

Figure 9. Maps of mean-event $\mathbf{E}_{\mathbf{0}}$ (or epsilon-sub-zero) in the western U.S. for the PSHA model of Frankel et al. (2002), for the $2 \%$ in 50 year probability of exceedance. Left side, for 1.0-s spectral acceleration. Right side, for the change in mean $\mathbf{E}_{0}$ from that associated with the previous PSHA model of Frankel et al. (1996).

Figure 10. Map of modal-event magnitude (or Mhat) in the California-Nevada region for the PSHA model of Frankel et al. (2002), for the $2 \%$ in 50 year probability of exceedance and for 1.0-s spectral acceleration. Light gray is used to denote areas where the dominant seismic-hazard source is Cascadia M9 megathrust. Medium and dark gray are used to denote regions where the dominant seismic-hazard source is a large San Andreas fault earthquake.

Figure 11. Map of modal-event distance (or Rhat) in the California-Nevada region for the PSHA model of Frankel et al. (2002), for the $2 \%$ in 50 year probability of exceedance and for 1.0-s spectral acceleration. Gray is used to denote regions where a nearby fault is the dominant source of seismic hazard.

Figure 12. Map of modal-event $\mathbf{E}_{\mathbf{0}}$ (or epsilon-sub-zero hat) in the CaliforniaNevada region for the PSHA model of Frankel et al. (2002), for the $2 \%$ in 50 year probability of exceedance and for 1.0-s spectral acceleration.

Figure 13. Map of modal-event magnitude (or Mhat) in the California-Nevada region for the PSHA model of Frankel et al. (2002), for the 2\% in 50 year probability of exceedance and for $0.2-\mathrm{s}$ or $5-\mathrm{Hz}$ spectral acceleration.

Figure 14. Map of modal-event distance (or Rhat) in the California-Nevada region for the PSHA model of Frankel et al. (2002), for the $2 \%$ in 50 year probability of exceedance and for $0.2-\mathrm{s}$ or $5-\mathrm{Hz}$ spectral acceleration.

Figure 15. Map of modal-event $\mathbf{E}_{\mathbf{0}}$ (or epsilon-sub-zero hat) in the CaliforniaNevada region for the PSHA model of Frankel et al. (2002), for the $2 \%$ in 50 year probability of exceedance and for $0.2-\mathrm{s}$ or $5-\mathrm{Hz}$ spectral acceleration.

Figure 16. Maps of mode-contribution-factor for California-Nevada region. Bottom left, for 1-s SA and for $2 \%$ in 50 year probability of exceedance. Bottom right, for 1-s SA and for $10 \%$ in 50 year probability of exceedance. Top left, for 0.2 -s SA and for $2 \%$ in 50 year probability of exceedance. Top right, for PGA and for $2 \%$ 
in 50 year probability of exceedance. Yellow to orange colors indicate that one source or a narrow range of sources (in magnitude and distance) contribute the majority of the seismic hazard. A light blue color indicates that many sources, over a broad range of magnitudes and/or distances, contribute to the seismic hazard at the site.

Figure 17. Map of modal-event magnitude (or Mhat) in the Pacific Northwest, principally Washington and Oregon, for the PSHA model of Frankel et al. (2002), for the $2 \%$ in 50 year probability of exceedance and for 1.0-s spectral acceleration. A white color is used to denote areas where the dominant seismichazard source is Cascadia M9 megathrust. Quaternary fault traces are gray.

Figure 18. Map of modal-event distance (or Rhat) in the Pacific Northwest, principally Washington and Oregon, for the PSHA model of Frankel et al. (2002), for the $2 \%$ in 50 year probability of exceedance and for 1.0-s spectral acceleration. Quaternary fault traces are white.

Figure 19. Map of modal-event $\mathbf{E}_{\mathbf{0}}$ (or epsilon-sub-zero hat) in the Pacific Northwest, for the PSHA model of Frankel et al. (2002), for the 2\% in 50 year probability of exceedance and for 1.0-s spectral acceleration. Quaternary fault traces are white.

Figure 20. Map of modal-event distance (or Rhat) in the Pacific Northwest, principally Washington and Oregon, for the PSHA model of Frankel et al. (2002), for the $2 \%$ in 50 year probability of exceedance and for $0.2-\mathrm{s}$ spectral acceleration. Quaternary fault traces are white.

Figure 21. Graphs depicting probabilistic seismic-hazard for a site in Portland, Oregon using the PSHA model of Frankel et al. (2002). All graphs are for 1-s spectral acceleration. Lower left, mean seismic hazard from all sources (solid curve) and for the modal source (dashed curve). Upper left, mean-event distance (km) (solid curve) and modal-event distance (dashed curve). Upper right, meanevent magnitude (M) (solid graph) and modal-event magnitude (dashed curve). Lower right, mean-event epsilon-sub-zero ( $\left.\mathbf{E}_{0}\right)$ (solid curve) and modal-event epsilon-sub-zero (dashed curve).

Figure 22. Maps of probabilistic 1-s spectral acceleration (or SA, units: $g$ ) for the Intermountain Seismic Belt region and for the $2 \%$ in 50 year probability of exceedance. Left side, for the PSHA model of Frankel et al. (2002). Right side, change in 1-s SA from the model of Frankel et al. (1996), mapped as the difference SA1 (2002) - SA1(1996).

Figure 23. Maps of deaggregated seismic hazard parameters for the Intermountain Seismic Belt region for 1-s SA, and for the 2\% in 50 year probability of exceedance. Left side, modal-event magnitude. Right side, modalevent distance $(\mathrm{km})$. Quaternary fault traces are white. 
Figure 24. Maps of modal-event magnitude (or Mhat) in the central and eastern U.S. for the PSHA model of Frankel et al. (2002), for the $2 \%$ in 50 year probability of exceedance. Left side, for 1.0-s spectral acceleration. Right side, for $0.2-\mathrm{s}$, or $5-\mathrm{Hz}$, spectral acceleration. Possible New Madrid fault locations are shown as three white traces.

Figure 25. Maps of modal-event distance $(R)$ in the central and eastern U.S. for the PSHA model of Frankel et al. (2002), for the $2 \%$ in 50 year probability of exceedance. Left side, for 1.0-s spectral acceleration. Right side, for 0.2-s, or 5$\mathrm{Hz}$, spectral acceleration.

Figure 26. Maps of modal-event $\mathbf{E}_{0}$ (or epsilon-sub-zero hat) in the central and eastern U.S. for the PSHA model of Frankel et al. (2002), for the $2 \%$ in 50 year probability of exceedance. Left side, for 1.0-s spectral acceleration. Right side, for $0.2-\mathrm{s}$, or $5-\mathrm{Hz}$, spectral acceleration.

Figure 27. Maps of modal-event magnitude (or Mhat) in the central and eastern U.S. for the PSHA model of Frankel et al. (2002), for the $2 \%$ in 50 year probability of exceedance. Left side, for 2.0-s spectral acceleration. Right side, for $0.1-\mathrm{s}$, or $10-\mathrm{Hz}$, spectral acceleration. Possible New Madrid fault locations are shown as three white traces.

Figure 28. Maps of modal-event $\boldsymbol{E}_{\mathbf{0}}$ (or epsilon-sub-zero hat) in the central and eastern U.S. for the PSHA model of Frankel et al. (2002) for peak horizontal ground acceleration, or PGA. Left side, for the $2 \%$ in 50 year probability of exceedance. Right side, for the $10 \%$ in 50 year probability of exceedance.

Figure 29. Maps of mean-event magnitude (or Mbar) in the central and eastern U.S. for the PSHA model of Frankel et al. (2002), for the $2 \%$ in 50 year probability of exceedance. Left side, for 1.0-s spectral acceleration. Right side, for $0.2-\mathrm{s}$, or $5-\mathrm{Hz}$, spectral acceleration.

Figure 30. Maps of mean-event distance (or Rbar) in the central and eastern U.S. for the PSHA model of Frankel et al. (2002), for the $2 \%$ in 50 year probability of exceedance. Left side, for 1.0-s spectral acceleration. Right side, for $0.2-\mathrm{s}$, or 5$\mathrm{Hz}$, spectral acceleration.

Figure 31. Maps of mean-event $\mathbf{E}_{\mathbf{0}}$ (or epsilon-sub-zero bar) in the central and eastern U.S. for the PSHA model of Frankel et al. (2002), for the $2 \%$ in 50 year probability of exceedance. Left side, for 1.0-s spectral acceleration. Right side, for $0.2-\mathrm{s}$, or $5-\mathrm{Hz}$, spectral acceleration.

Figure 32. Deaggregated seismic hazard for 0.2-s spectral acceleration with $2 \%$ in 50 year probability of exceedance in the New Madrid Seismic Zone and vicinity. Top left, spectral acceleration (units, $g$ ) for PSHA model of Frankel et al. 
(2002). Top right, difference in spectral acceleration from the PSHA model of Frankel et al. (1996). Bottom left, modal-event $\mathbf{E}_{0}$ (or epsilon-sub-zero hat).

Bottom right, modal-event distance (or Rhat, units: $\mathrm{km}$ ). Possible locations of NMSZ fault system are shown as three white traces.

Figure 33. Deaggregated seismic hazard for 0.2-s spectral acceleration (or SA) with $2 \%$ in 50 year probability of exceedance in South Carolina and vicinity. Top left, spectral acceleration (units, $g$ ) for PSHA model of Frankel et al. (2002). Top right, difference in spectral acceleration from the PSHA model of Frankel et al. (1996) expressed as the ratio SA(2002)/SA(1996). Bottom left, modal-event magnitude. Bottom right, modal-event distance (units: $\mathrm{km}$ ). Rivers are shown as blue lines. 